\title{
On a Theorem of Khan in a Generalized Metric Space
}

\author{
Jamshaid Ahmad, ${ }^{1}$ Muhammad Arshad, ${ }^{2}$ and Calogero Vetro ${ }^{3}$ \\ ${ }^{1}$ Department of Mathematics, COMSATS Institute of Information Technology, Chak Shahzad, Islamabad 44000, Pakistan \\ ${ }^{2}$ Department of Mathematics, International Islamic University, H-10, Islamabad 44000, Pakistan \\ ${ }^{3}$ Dipartimento di Matematica e Informatica, Università degli Studi di Palermo, Via Archirafi, 34, 90123 Palermo, Italy
}

Correspondence should be addressed to Calogero Vetro; cvetro@math.unipa.it

Received 25 August 2012; Revised 20 January 2013; Accepted 23 January 2013

Academic Editor: Ying Hu

Copyright (C) 2013 Jamshaid Ahmad et al. This is an open access article distributed under the Creative Commons Attribution License, which permits unrestricted use, distribution, and reproduction in any medium, provided the original work is properly cited.

Existence and uniqueness of fixed points are established for a mapping satisfying a contractive condition involving a rational expression on a generalized metric space. Several particular cases and applications as well as some illustrative examples are given.

\section{Introduction and Preliminaries}

In the last decades, several attempts have been made in order to generalize the concept of metric space, and many important results have been reported. For instance, see quasi metric spaces [1], generalized quasi metric spaces [2], pseudometric spaces ([3], Chapter 2), approach spaces [4], $m$-spaces [5], inframetric spaces [6], and $G$-metric spaces [7]. Sometimes, as in $[8,9]$, even the very notion of generalized metric spaces (or even gms [10]) is used, but it has a different meaning. In 2000, Branciari [11] introduced the notion of generalized metric space where the triangle inequality of a metric space is replaced by a rectangular inequality involving four terms instead of three. He also extended the Banach's contraction principle in such spaces. In 2008, Azam and Arshad [12] obtained sufficient conditions for existence of unique fixed point of Kannan type mappings defined on generalized metric spaces. Recently, Samet [13] and Sarma et al. [14] showed that some propositions in [11] are not true. Moreover, in [14], a rigorous and nice proof of the Banach's contraction principle is presented, by assuming that the generalized metric space is Hausdorff. Afterwards, many authors studied various existence theorems of fixed points in such spaces. For more details about fixed point theory in generalized metric spaces, we refer the reader to $[13,15-24]$.

On the other hand, in [25] Khan proved the following fixed point theorem.
Theorem 1. Let $(X, d)$ be a complete metric space and let $T$ be a self-mapping on $X$ that satisfies the following contractive condition:

$$
d(T x, T y) \leq \mu \frac{d(x, T x) d(x, T y)+d(y, T x) d(y, T y)}{d(x, T y)+d(y, T x)}
$$

for all $x, y \in X$ and for some $\mu \in[0,1)$. Then $T$ has a unique fixed point in $X$.

Remark 2. In (1) if the denominator vanishes, then $x=T y$ and $y=T x$ and consequently also the numerator vanishes. Moreover, we have $d(T x, T y)=d(y, x)$, and so the contractive condition is not well defined.

The aim of this paper is to give a version of Theorem 1 in the setting of generalized metric spaces.

The following definitions will be needed in the sequel.

Definition 3 (see [11]). Let $X$ be a nonempty set and let $d$ : $X \times X \rightarrow[0,+\infty)$ be a mapping such that for all $x, y \in X$ and for all distinct points $u, v \in X$, each of them different from $x$ and $y$, one has

$$
\begin{aligned}
& \text { (gm1) } d(x, y)=0 \text { if and only if } x=y, \\
& (\mathrm{gm} 2) d(x, y)=d(y, x), \\
& (\mathrm{gm} 3) d(x, y) \leq d(x, u)+d(u, v)+d(v, y) \text { (the rectangular } \\
& \text { inequality). }
\end{aligned}
$$


Then $d$ is called generalized metric and the pair $(X, d)$ is called generalized metric space (gms, for short). Note that the rectangular inequality and simple induction show that this inequality holds with $2 l+1$ terms, where $l \geq 1$.

The next example gives a method of construction a new generalized metric space from a family of given generalized metric spaces.

Example 4. Let $\left\{\left(X_{n}, d_{n}\right): n \in J \subset \mathbb{N}\right\}$ be a family of disjoint generalized metric spaces and let $X=\bigcup\left\{X_{n}: n \in J\right\}$. Define $d: X \times X \rightarrow[0,+\infty)$ by $d(x, y)=d(y, x)$ with

$$
\begin{aligned}
& d(x, y) \\
& \quad= \begin{cases}d_{n}(x, y), & \text { if } x, y \in X_{n}, n \in J, \\
1, & \text { if } x \in X_{n}, y \in X_{m}, m, n \in J, m \neq n .\end{cases}
\end{aligned}
$$

Then, $(X, d)$ is a gms.

By referring to the Minkowski's inequality for sums, we give an example of a gms that is not a metric space.

Example 5. Let $X=\mathbb{R}^{2}, p \in(0,1)$ and define the generalized metric $d: X \times X \rightarrow[0,+\infty)$ by

$$
d(x, y)= \begin{cases}\left(\sum_{i=1}^{2}\left|x_{i}-y_{i}\right|^{p}\right)^{1 / p}, & \text { if } x_{i}, y_{i} \in\{0,1\} \\ \sum_{i=1}^{2}\left|x_{i}-y_{i}\right|, & \text { otherwise. }\end{cases}
$$

Clearly, (gm1) and (gm2) are obvious. Also (gm3) is immediate if at least one between $x_{i}$ and $y_{i}$ is not in $\{0,1\}$. Then, consider $A=[0,0]^{T}, B=[0,1]^{T}, C=[1,0]^{T}$, and $D=[1,1]^{T}$ so that we have $d(A, B)=d(A, C)=d(C, D)=d(B, D)=1$ and $d(A, D)=d(C, B)=2^{1 / p}$. Note that

$$
d(C, B)=2^{1 / p}<2+2^{1 / p}=d(C, D)+d(A, D)+d(A, B)
$$

and so (gm3) holds true. Then $(X, d)$ is a gms. On the other hand, $d(A, B)+d(A, C)=2<2^{1 / p}=d(C, B)$ since $p \in(0,1)$. Here, the triangle inequality is violated; that is, $(X, d)$ is not a metric space.

Definition 6 (see [11]). Let $(X, d)$ be a gms, and let $\left\{x_{n}\right\}$ be a sequence in $X$ and $x \in X$. We say that $\left\{x_{n}\right\}$ is gms convergent to $x$ if and only if $d\left(x_{n}, x\right) \rightarrow 0$ as $n \rightarrow+\infty$. We denote this by $x_{n} \rightarrow x$.

Definition 7 (see [11]). Let $(X, d)$ be a gms and let $\left\{x_{n}\right\}$ be a sequence in $X$. We say that $\left\{x_{n}\right\}$ is a gms Cauchy sequence if and only if for each $\epsilon>0$ there exists a natural number $n(\epsilon)$ such that $d\left(x_{n}, x_{m}\right)<\epsilon$ for all $n>m>n(\epsilon)$.

Definition 8 (see [11]). Let $(X, d)$ be a gms. $(X, d)$ is called a complete gms if every gms Cauchy sequence is gms convergent in $X$.
Definition 9. Let $X$ be a set and let $\tau$ be a topology on $X$. $(X, \tau)$ is a Hausdorff topological space, if for every $x, y \in X$ with $x \neq y$ there are open subsets $U, V$ of $X$ such that $x \in U$, $y \in V$, and $U, V$ are disjoint. Equivalently, a topological space $(X, \tau)$ is Hausdorff if and only if every convergent net in $X$ has a unique limit, and in particular the limit of a convergent sequence is unique.

Now, we recall an example of a complete gms that is not Hausdorff.

Example 10 (see [14]). Let $X=\{0,2\} \cup\{1 / n: n \in \mathbb{N}\}$ and define $d: X \times X \rightarrow[0,+\infty)$ by $d(x, y)=d(y, x)$ with

$$
d(x, y)= \begin{cases}0, & \text { if } x=y, \\ 1, & \text { if } x, y \in\{0,2\} \text { or } \\ & x, y \in\{1 / n: n \in \mathbb{N}\}, x \neq y, \\ y, & \text { if } x \in\{0,2\}, y \in\{1 / n: n \in \mathbb{N}\}\end{cases}
$$

Then $(X, d)$ is a complete gms.

\section{Main Results}

Our main theorem is essentially inspired by Khan [25]. More precisely, we state and prove the following result.

Theorem 11. Let $(X, d)$ be a complete gms and let $T: X \rightarrow X$ be a self-mapping such that

$$
\begin{aligned}
& d(T x, T y) \\
& \leq\left\{\begin{array}{c}
\lambda d(x, y) \\
+\mu \frac{d(x, T x) d(x, T y)+d(y, T x) d(y, T y)}{d(x, T y)+d(y, T x)} \\
\text { if } d(x, T y)+d(y, T x) \neq 0, \\
\text { if } d(x, T y)+d(y, T x)=0,
\end{array}\right.
\end{aligned}
$$

for all $x, y \in X$ and $x \neq y$, and for some $\lambda, \mu \in[0,1)$ with $\lambda+\mu<1$. Then $T$ has a unique fixed point in $X$.

Proof. Let $x_{0} \in X$ be an arbitrary point. Define $x_{n+1}=T x_{n}=$ $T^{n+1} x_{0}$, for $n=0,1,2, \ldots$. If $x_{n}=x_{n-1}$ for some $n \geq 1$, then $x_{n-1}=T x_{n-1}$ and hence $x_{n-1}$ is a fixed point of $T$. This completes the proof. Therefore, we suppose $x_{n} \neq x_{n-1}$ for all $n \geq 1$ and distinguish two cases. 
Case 1. Assume that $d\left(x_{n-1}, T x_{n}\right)+d\left(x_{n}, T x_{n-1}\right) \neq 0$, for $n=$ $0,1,2, \ldots$ Then

$$
\begin{aligned}
d\left(x_{n}, x_{n+1}\right) & \\
= & d\left(T x_{n-1}, T x_{n}\right) \\
\leq & \lambda d\left(x_{n-1}, x_{n}\right)+\mu\left(d\left(x_{n-1}, T x_{n-1}\right) d\left(x_{n-1}, T x_{n}\right)\right. \\
& \left.+d\left(x_{n}, T x_{n-1}\right) d\left(x_{n}, T x_{n}\right)\right) \\
\quad & \left.\quad d\left(x_{n-1}, T x_{n}\right)+d\left(x_{n}, T x_{n-1}\right)\right)^{-1} \\
= & \lambda d\left(x_{n-1}, x_{n}\right) \quad+\mu\left(d\left(x_{n-1}, x_{n}\right) d\left(x_{n-1}, x_{n+1}\right)\right. \\
\quad & \left.\quad+d\left(x_{n}, x_{n}\right) d\left(x_{n}, x_{n+1}\right)\right) \\
\quad & \left(d\left(x_{n-1}, x_{n+1}\right)+d\left(x_{n}, x_{n}\right)\right)^{-1},
\end{aligned}
$$

that is,

$$
d\left(x_{n}, x_{n+1}\right) \leq \lambda d\left(x_{n-1}, x_{n}\right)+\mu d\left(x_{n-1}, x_{n}\right),
$$

or equivalently

$$
d\left(T^{n} x_{0}, T^{n+1} x_{0}\right) \leq(\lambda+\mu) d\left(T^{n-1} x_{0}, T^{n} x_{0}\right) .
$$

Thus in general, for $n \geq 1$, we have

$$
\begin{aligned}
d\left(T^{n} x_{0}, T^{n+1} x_{0}\right) & \leq(\lambda+\mu) d\left(T^{n-1} x_{0}, T^{n} x_{0}\right) \\
& \leq(\lambda+\mu)^{2} d\left(T^{n-2} x_{0}, T^{n-1} x_{0}\right) \\
& \leq \cdots \\
& \leq(\lambda+\mu)^{n} d\left(x_{0}, T x_{0}\right),
\end{aligned}
$$

and so, since $\lambda+\mu<1, d\left(T^{n} x_{0}, T^{n+1} x_{0}\right) \rightarrow 0$ as $n \rightarrow+\infty$. Now, we consider the following two subcases.

Subcase 1.1. We assume that $T^{m} x_{0}=T^{n} x_{0}$ for some $m, n \in \mathbb{N}$ with $m \neq n$. Letting $m>n$, then $T^{m-n}\left(T^{n} x_{0}\right)=T^{n} x_{0}$, that is, $T^{k} y=y$ where $k=m-n, y=T^{n} x_{0}$. Now, if $k>1$, from (6) we have

$$
\begin{aligned}
d(y, T y) & =d\left(T^{k} y, T^{k+1} y\right) \\
& \leq \cdots \\
& \leq(\lambda+\mu)^{k} d(y, T y),
\end{aligned}
$$

that implies $y=T y$, since $\lambda+\mu<1$.

Subcase 1.2. We assume that $T^{m} x_{0} \neq T^{n} x_{0}$ for all $m, n \in \mathbb{N}$ with $m \neq n$. Clearly we have

$$
d\left(T^{n} x_{0}, T^{n+1} x_{0}\right) \leq(\lambda+\mu)^{n} d\left(x_{0}, T x_{0}\right)
$$

and, after routine calculations, it is also easy to obtain

$$
\begin{aligned}
d\left(T^{n} x_{0}, T^{n+2} x_{0}\right) & \\
\leq & \lambda d\left(T^{n-1} x_{0}, T^{n+1} x_{0}\right) \\
& +\mu\left(d\left(T^{n-1} x_{0}, T^{n} x_{0}\right) d\left(T^{n-1} x_{0}, T^{n+2} x_{0}\right)\right. \\
& \left.+d\left(T^{n+1} x_{0}, T^{n} x_{0}\right) d\left(T^{n+1} x_{0}, T^{n+2} x_{0}\right)\right) \\
& \times\left(d\left(T^{n-1} x_{0}, T^{n+2} x_{0}\right)+d\left(T^{n+1} x_{0}, T^{n} x_{0}\right)\right) \\
\leq & \lambda d\left(T^{n-1} x_{0}, T^{n+1} x_{0}\right)+\mu d\left(T^{n-1} x_{0}, T^{n} x_{0}\right) \\
& +\mu d\left(T^{n+1} x_{0}, T^{n+2} x_{0}\right) \\
\leq & \lambda d\left(T^{n-1} x_{0}, T^{n+1} x_{0}\right)+\mu(\lambda+\mu)^{n-1} d\left(x_{0}, T x_{0}\right) \\
& +\mu(\lambda+\mu)^{n+1} d\left(x_{0}, T x_{0}\right) \\
\leq & \lambda d\left(T^{n-1} x_{0}, T^{n+1} x_{0}\right)+2(\lambda+\mu)^{n-1} d\left(x_{0}, T x_{0}\right) .
\end{aligned}
$$

Using the previous inequality, we get

$$
\begin{aligned}
d\left(T^{n} x_{0}, T^{n+2} x_{0}\right) \leq & \lambda^{2} d\left(T^{n-2} x_{0}, T^{n} x_{0}\right)+2 \lambda(\lambda+\mu)^{n-2} \\
& \times d\left(x_{0}, T x_{0}\right)+2(\lambda+\mu)^{n-1} d\left(x_{0}, T x_{0}\right) \\
\leq & \lambda^{2} d\left(T^{n-2} x_{0}, T^{n} x_{0}\right) \\
& +4(\lambda+\mu)^{n-1} d\left(x_{0}, T x_{0}\right)
\end{aligned}
$$

and hence

$$
\begin{aligned}
d\left(T^{n} x_{0}, T^{n+2} x_{0}\right) \leq & \lambda^{n} d\left(x_{0}, T^{2} x_{0}\right) \\
& +2 n(\lambda+\mu)^{n-1} d\left(x_{0}, T x_{0}\right) .
\end{aligned}
$$

Now, if $m>2$ is odd, then writing $m=2 l+1, l \geq 1$ and using the fact that $T^{m} x_{0} \neq T^{n} x_{0}$ for $m, n \in \mathbb{N}$ with $m \neq n$, we can easily show that

$$
\begin{aligned}
& d\left(T^{n} x_{0}, T^{n+m} x_{0}\right) \\
& \leq d\left(T^{n} x_{0}, T^{n+1} x_{0}\right)+d\left(T^{n+1} x_{0}, T^{n+2} x_{0}\right) \\
&+\cdots+d\left(T^{n+2 l} x_{0}, T^{n+2 l+1} x_{0}\right) \\
& \leq(\lambda+\mu)^{n} d\left(x_{0}, T x_{0}\right)+(\lambda+\mu)^{n+1} d\left(x_{0}, T x_{0}\right) \\
&+\cdots+(\lambda+\mu)^{n+2 l} d\left(x_{0}, T x_{0}\right) \\
& \leq \frac{(\lambda+\mu)^{n}}{1-\lambda-\mu} d\left(x_{0}, T x_{0}\right) .
\end{aligned}
$$


On the other hand, if $m>2$ is even, then writing $m=2 l, l \geq 2$ and using the fact that $T^{m} x_{0} \neq T^{n} x_{0}$ for $m, n \in \mathbb{N}$ with $m \neq n$, we can easily show that

$$
\begin{aligned}
& d\left(T^{n} x_{0}, T^{n+m} x_{0}\right) \\
& \leq d\left(T^{n} x_{0}, T^{n+2} x_{0}\right)+d\left(T^{n+2} x_{0}, T^{n+3} x_{0}\right) \\
&+\cdots+d\left(T^{n+2 l-1} x_{0}, T^{n+2 l} x_{0}\right) \\
& \leq \lambda^{n} d\left(x_{0}, T^{2} x_{0}\right)+2 n(\lambda+\mu)^{n-1} d\left(x_{0}, T x_{0}\right) \\
&+(\lambda+\mu)^{n+2} d\left(x_{0}, T x_{0}\right)+\cdots \\
&+(\lambda+\mu)^{n+2 l-1} d\left(x_{0}, T x_{0}\right) \\
& \leq \lambda^{n} d\left(x_{0}, T^{2} x_{0}\right)+2 n(\lambda+\mu)^{n-1} d\left(x_{0}, T x_{0}\right) \\
&+\frac{(\lambda+\mu)^{n+2}}{1-\lambda-\mu} d\left(x_{0}, T x_{0}\right) .
\end{aligned}
$$

Thus, combining all the cases, for all $m, n \in \mathbb{N}$ we have

$$
\begin{aligned}
d\left(T^{n} x_{0}, T^{n+m} x_{0}\right) \leq & \frac{(\lambda+\mu)^{n}}{1-\lambda-\mu} d\left(x_{0}, T x_{0}\right)+\lambda^{n} d\left(x_{0}, T^{2} x_{0}\right) \\
& +2 n(\lambda+\mu)^{n-1} d\left(x_{0}, T x_{0}\right)
\end{aligned}
$$

Therefore, $d\left(T^{n} x_{0}, T^{n+m} x_{0}\right) \rightarrow 0$ as $n \rightarrow+\infty$. This implies that $\left\{x_{n}\right\}$ is a Cauchy sequence in $X$. Since $X$ is complete, there exists a $u \in X$ such that $x_{n} \rightarrow u$. If $d\left(u, T^{n} x_{0}\right)+d\left(T^{n-1} x_{0}, T u\right)=0$, for some $n \geq 1$, then $u=T^{n} x_{0}$, and, by (6), we get $d\left(T u, T^{n} x_{0}\right)=0$. It follows that $u=T^{n} x_{0}=T u$; that is, $u$ is a fixed point of $T$. Then, without loss of generality we can assume that $d\left(u, T^{n} x_{0}\right)+$ $d\left(T^{n-1} x_{0}, T u\right)>0$ for all $n \geq 1$. Now, if $u \neq T u, T u \neq T^{n} x_{0}$ and $T^{n+1} x_{0} \neq u$, by the rectangular inequality we have

$$
\begin{aligned}
d(T u, u) & \\
\leq & d\left(T u, T^{n} x_{0}\right)+d\left(T^{n} x_{0}, T^{n+1} x_{0}\right)+d\left(T^{n+1} x_{0}, u\right) \\
\leq & \lambda d\left(u, T^{n-1} x_{0}\right) \\
& +\mu\left(d(u, T u) d\left(u, T^{n} x_{0}\right)+d\left(T^{n-1} x_{0}, T u\right)\right. \\
& \left.\quad \times d\left(T^{n-1} x_{0}, T^{n} x_{0}\right)\right) \\
& \times\left(d\left(u, T^{n} x_{0}\right)+d\left(T^{n-1} x_{0}, T u\right)\right)^{-1} \\
& +(\lambda+\mu)^{n} d\left(x_{0}, T x_{0}\right)+d\left(T^{n+1} x_{0}, u\right) \\
\leq & \lambda d\left(u, T^{n-1} x_{0}\right)+\mu\left(d(u, T u)+d\left(T^{n-1} x_{0}, T^{n} x_{0}\right)\right) \\
& +(\lambda+\mu)^{n} d\left(x_{0}, T x_{0}\right)+d\left(T^{n+1} x_{0}, u\right)
\end{aligned}
$$

$$
\begin{aligned}
\leq & \lambda d\left(u, T^{n-1} x_{0}\right)+\mu\left(d(u, T u)+(\lambda+\mu)^{n-1} d\left(x_{0}, T x_{0}\right)\right) \\
& +(\lambda+\mu)^{n} d\left(x_{0}, T x_{0}\right)+d\left(T^{n+1} x_{0}, u\right)
\end{aligned}
$$

Letting $n \rightarrow+\infty$, since $T^{n} x_{0} \rightarrow u$, we obtain easily ( $1-$ $\mu) d(u, T u) \leq 0$ that leads to a contradiction since $\mu<1$ and so must be $u=T u$.

On the other hand, if $T u=T^{n} x_{0}$ for every $n \in J \subset \mathbb{N}$ and $J$ is infinite, then

$$
\lim _{n \rightarrow+\infty, n \in J} d(T u, u)=\lim _{n \rightarrow+\infty, n \in J} d\left(T^{n} x_{0}, u\right)=0,
$$

that implies $d(T u, u)=0$ and so $T u=u$. If $J$ is finite, then $T^{n-1} x_{0}=u$ (or generally $T^{n+1} x_{0}=u$ ) only for a finite set of values of $n$, and therefore (19) holds for all $n$ large enough. Now, we show that $T$ has a unique fixed point. For this, we assume that $u^{*}$ is another fixed point of $T$ in $X$ such that $d\left(u, u^{*}\right)+d\left(u^{*}, u\right)>0$. By (6) we have

$$
\begin{aligned}
d\left(u, u^{*}\right) & \\
= & d\left(T u, T u^{*}\right) \\
\leq & \lambda d\left(u, u^{*}\right) \\
& +\mu \frac{d(u, T u) d\left(u, T u^{*}\right)+d\left(u^{*}, T u\right) d\left(u^{*}, T u^{*}\right)}{d\left(u, T u^{*}\right)+d\left(u^{*}, T u\right)} \\
& =\lambda d\left(u, u^{*}\right)+\mu \frac{d(u, u) d\left(u, u^{*}\right)+d\left(u^{*}, u\right) d\left(u^{*}, u^{*}\right)}{d\left(u, u^{*}\right)+d\left(u^{*}, u\right)},
\end{aligned}
$$

or, equivalently, $(1-\lambda) d\left(u, u^{*}\right) \leq 0$ that leads to a contradiction and hence $u=u^{*}$.

Case 2. Assume that $d\left(x_{n-1}, T x_{n}\right)+d\left(x_{n}, T x_{n-1}\right)=0$, for some $n$. By condition (6), it follows that $d\left(T x_{n-1}, T x_{n}\right)=0$ and hence $x_{n}=T x_{n}$. This completes the proof of the existence of a fixed point of $T$, say $u$.

The uniqueness follows as in Case 1.

As consequence of Theorem 11, we give the following corollary.

Corollary 12. Let $(X, d)$ be a complete gms and let $T: X \rightarrow$ $X$ be a self-mapping such that

$$
\begin{aligned}
& d\left(T^{n} x, T^{n} y\right) \\
& \leq\left\{\begin{array}{c}
\lambda d(x, y) \\
+\mu \frac{d\left(x, T^{n} x\right) d\left(x, T^{n} y\right)+d\left(y, T^{n} x\right) d\left(y, T^{n} y\right)}{d\left(x, T^{n} y\right)+d\left(y, T^{n} x\right)} \\
\text { if } d\left(x, T^{n} y\right)+d\left(y, T^{n} x\right) \neq 0, \\
0, \quad \text { if } d\left(x, T^{n} y\right)+d\left(y, T^{n} x\right)=0,
\end{array}\right.
\end{aligned}
$$

for all $x, y \in X$ and $x \neq y$, for some $n \geq 1$ and for some $\lambda, \mu \in$ $[0,1)$ with $\lambda+\mu<1$. Then $T$ has a unique fixed point in $X$. 
Proof. By Theorem 11, let $u$ be the unique fixed point of the mapping $T^{n}$. Then, we have $T^{n}(T u)=T\left(T^{n} u\right)=T u$ and so $T u$ is a fixed point of $T^{n}$. Therefore, by uniqueness of the fixed point it must be that $T u=u$.

By setting $\mu=0$ in Corollary 12, we draw the following result which can be viewed as an extension of Bryant's theorem [26] to generalized metric spaces.

Corollary 13. Let $(X, d)$ be a complete gms and let $T: X \rightarrow$ $X$ be a self-mapping such that

$$
d\left(T^{n} x, T^{n} y\right) \leq \lambda d(x, y)
$$

for all $x, y \in X$ and $x \neq y$, for some $n \geq 1$ and for some $\lambda \epsilon$ $[0,1)$. Then $T$ has a unique fixed point in $X$.

Proof. Note that if $d\left(x, T^{n} y\right)+d\left(y, T^{n} x\right)=0$, then $x=T^{n} y$ and $y=T^{n} x$ and so from (23) we have

$$
d\left(T^{n} x, T^{n} y\right)=d(x, y) \leq \lambda d(x, y)
$$

Since $\lambda<1$, this implies $x=y$, but by hypothesis, condition (23) must hold true only for all $x, y \in X$ with $x \neq y$. Then, without loss of generality we can assume that $d\left(x, T^{n} y\right)+$ $d\left(y, T^{n} x\right) \neq 0$. The rest of the proof is a direct consequence of Corollary 12 and Theorem 11.

\section{Our first example illustrates Theorem 11.}

Example 14. Let $X=\{1,-1, i,-i\}$ and define the generalized metric $d: X \times X \rightarrow[0,+\infty)$ by $d(x, y)=d(y, x)$ with

$$
d(x, y)= \begin{cases}0, & \text { if } x=y \\ 1, & \text { if } x \in\{1,-1\}, y=i \\ 3, & \text { if } x, y \in\{1,-1\}, x \neq y \\ 5, & \text { otherwise. }\end{cases}
$$

By routine calculations, it is easy to check that (gm3) holds and so $d$ is a generalized metric; obviously, $(X, d)$ is complete. On the other hand, $d$ does not satisfy the triangle inequality. Indeed, we get

$$
3=d(1,-1)>d(1, i)+d(i,-1)=2 .
$$

Now, define $T: X \rightarrow X$ by

$$
T x= \begin{cases}i, & \text { if } x \neq-i \\ 1, & \text { if } x=-i\end{cases}
$$

The reader can easily show that the mapping $T$ satisfies the contractive condition of Theorem 11 with $\lambda=1 / 3$ and $\mu=$ $1 / 4$, for example. Then, $x=i$ is the unique fixed point of $T$.

The following example illustrates Corollary 12 but essentially shows the usefulness of Bryant's theorem in respect of Banach's contraction principle.
Example 15. Let $X=[0,2]$ and $A=\{1 / 2,2 / 3,3 / 4,4 / 5\}$. Define the generalized metric $d: X \times X \rightarrow[0,+\infty)$ by $d(x, y)=d(y, x)$ with

$$
\begin{gathered}
d\left(\frac{1}{2}, \frac{2}{3}\right)=d\left(\frac{3}{4}, \frac{4}{5}\right)=0.2, \\
d\left(\frac{1}{2}, \frac{4}{5}\right)=d\left(\frac{2}{3}, \frac{3}{4}\right)=0.3, \\
d\left(\frac{1}{2}, \frac{3}{4}\right)=d\left(\frac{2}{3}, \frac{4}{5}\right)=0.6, \\
d\left(\frac{1}{2}, \frac{1}{2}\right)=d\left(\frac{2}{3}, \frac{2}{3}\right)=d\left(\frac{3}{4}, \frac{3}{4}\right)=d\left(\frac{4}{5}, \frac{4}{5}\right)=0, \\
d(x, y)=|x-y| \quad \text { if } x, y \in X \backslash A \text { or } x \in A, y \in X \backslash A .
\end{gathered}
$$

By routine calculations, it is easy to check that (gm3) holds and so $d$ is a generalized metric. On the other hand, $d$ does not satisfy the triangle inequality on $A$. Indeed, we get

$$
0.6=d\left(\frac{1}{2}, \frac{3}{4}\right) \geq d\left(\frac{1}{2}, \frac{2}{3}\right)+d\left(\frac{2}{3}, \frac{3}{4}\right)=0.5 \text {. }
$$

Next, we show that $(X, d)$ is complete. Indeed, if there exists $m \in \mathbb{N}$ such that $x_{m}=x_{n}$ for all $n \geq m$, then the sequence $\left\{x_{n}\right\}$ is Cauchy. Now, we assume that for all $m \in \mathbb{N}$ there exists $n \geq m$ such that $x_{m} \neq x_{n}$. Let $\varepsilon<0.2$ be fixed and assume that there exists $n(\varepsilon)$ such that $d\left(x_{n}, x_{m}\right)<\varepsilon$. This implies that $\left\{x_{n}: n \geq n(\varepsilon)\right\} \cap A$ is at most singleton (each two distinct points in $A$ have distance greater than $\varepsilon$, by definition). Also by definition of $d$, it follows that $\left\{x_{n}\right\}$ is Cauchy in $X$, endowed with the usual metric of real numbers, and so convergent in $[0,2]$. Consequently, the same holds in the gms $(X, d)$.

Now, define $T: X \rightarrow X$ by

$$
T x=\left\{\begin{array}{l}
0, \text { if } x \in\left\{\frac{1}{2}, \frac{2}{3}, \frac{3}{4}\right\} \\
2, \text { if } x=\frac{4}{5} \\
1, \text { otherwise. }
\end{array}\right.
$$

Then, for $x=1 / 2$ and $y=4 / 5$, we get

$$
d\left(T\left(\frac{1}{2}\right), T\left(\frac{4}{5}\right)\right)=d(0,2)=2 \leq \lambda d\left(\frac{1}{2}, \frac{4}{5}\right)=\lambda(0.3),
$$

which leads to a contradiction since $\lambda \in[0,1)$. Therefore, the Banach's contraction principle is not applicable in this case. On the other hand, since $T^{2} x=1$, we have

$$
0=d\left(T^{2} x, T^{2} y\right) \leq \lambda d(x, y),
$$

which shows that $T$ satisfies the contractive condition of Corollary 12 and $x=1$ is the unique fixed point of $T$.

Finally, as an application of Theorem 11 we give the following result. 
Corollary 16. Let $(X, d)$ be a complete gms and let $T: X \rightarrow$ $X$ be a self-mapping satisfying (6). If $S: X \rightarrow X$ is a selfmapping such that $S T=T S$, then $T$ and $S$ have a unique common fixed point in $X$; that, is there exists $u \in X$ such that $u=T u=S u$.

Proof. By Theorem 11, let $u$ be the unique fixed point of the mapping $T$. Then, we have $T(S u)=S(T u)=S u$ and so $S u$ is a fixed point of $T$. Therefore, by uniqueness of the fixed point it must be that $S u=u=T u$.

\section{Acknowledgments}

The authors would like to thank the editor and reviewers for their helpful comments. The third author is supported by Università degli Studi di Palermo, Local University Project R.S. ex $60 \%$.

\section{References}

[1] M. B. Smyth, "Totally bounded spaces and compact ordered spaces as domains of computation," in Topology and Category Theory in Computer Science, pp. 207-229, Oxford University Press, New York, NY, USA, 1991.

[2] L. Kikina and K. Kikina, "Two fixed point theorems on a class of generalized quasi-metric spaces," Journal of Computational Analysis and Applications, vol. 14, pp. 950-957, 2012.

[3] R. C. Freiwald, Introduction to set theory and topology, lecture notes, Washington University in St. Louis, 2010, http://www .math.wustl.edu/ freiwald/topologynotes.html.

[4] R. Lowen, Approach Spaces: The Missing Link in the TopologyUniformity-Metric Triad, Oxford Mathematical Monographs, Oxford, UK, 1997.

[5] D. Reem and S. Reich, "Zone and double zone diagrams in abstract spaces," Colloquium Mathematicum, vol. 115, pp. 129$145,2009$.

[6] P. Fraigniaud, E. Lebhar, and L. Viennot, "The inframetric model for the internet," in Proceedings of the 27th IEEE Conference on Computer Communications (INFOCOM '08), pp. 10851093, April 2008.

[7] Z. Mustafa and B. Sims, "A new approach to generalized metric spaces," Journal of Nonlinear and Convex Analysis, vol. 7, no. 2, pp. 289-297, 2006.

[8] C. F. K. Jung, “On generalized complete metric spaces," Bulletin of the American Mathematical Society, vol. 75, no. 2, pp. 113-116, 1969.

[9] B. Margolis, "On some fixed points theorems in generalized complete metric spaces," Bulletin of the American Mathematical Society, vol. 74, pp. 275-282, 1968.

[10] M. M. Bonsangue, F. van Breugel, and J. J. M. M. Rutten, "Generalized metric spaces: completion, topology, and powerdomains via the Yoneda embedding," Theoretical Computer Science, vol. 193, no. 1-2, pp. 1-51, 1998.

[11] A. Branciari, "A fixed point theorem of Banach-Caccioppoli type on a class of generalized metric spaces," Publicationes Mathematicae, vol. 57, no. 1-2, pp. 31-37, 2000.

[12] A. Azam and M. Arshad, "Kannan fixed point theorem on generalized metric spaces," The Journal of Nonlinear Science and Applications, vol. 1, no. 1, pp. 45-48, 2008.
[13] B. Samet, "Discussion on "a fixed point theorem of BanachCaccioppoli type on a class of generalized metric spaces" by A. Branciari," Publicationes Mathematicae, vol. 76, no. 3-4, pp. 493494, 2010.

[14] I. R. Sarma, J. M. Rao, and S. S. Rao, "Contractions over generalized metric spaces," The Journal of Nonlinear Science and Applications, vol. 2, no. 3, pp. 180-182, 2009.

[15] C. M. Chen and C. H. Chen, "Periodic points for the weak contraction mappings in complete generalized metric spaces," Fixed Point Theory and Applications, vol. 2012, article 79, 2012.

[16] P. Das, "A fixed point theorem in a generalized metric space," Soochow Journal of Mathematics, vol. 33, no. 1, pp. 33-39, 2007.

[17] P. Das and L. K. Dey, "Fixed point of contractive mappings in generalized metric spaces," Mathematica Slovaca, vol. 59, no. 4, pp. 499-504, 2009.

[18] C. Di Bari and P. Vetro, "Common fixed points in generalized metric spaces," Applied Mathematics and Computation, vol. 218, no. 13, pp. 7322-7325, 2012.

[19] A. Fora, A. Bellour, and A. Al-Bsoul, "Some results in fixed point theory concerning generalized metric spaces," Matematički Vesnik, vol. 61, no. 3, pp. 203-208, 2009.

[20] D. S. Jaggi, "Some fixed point theorems," Indian Journal of Pure and Applied Mathematics, vol. 8, pp. 223-230, 1977.

[21] M. S. Khan, "Some fixed point theorems," Indian Journal of Pure and Applied Mathematics, vol. 8, pp. 1511-1514, 1975.

[22] H. Lakzian and B. Samet, "Fixed points for $(\psi, \phi)$-weakly contractive mappings in generalized metric spaces," Applied Mathematics Letters, vol. 25, no. 5, pp. 902-906, 2012.

[23] D. Mihet, "On Kannan fixed point principle in generalized metric spaces," The Journal of Nonlinear Science and Applications, vol. 2, no. 2, pp. 92-96, 2009.

[24] B. Samet, "A fixed point theorem in a generalized metric space for mappings satisfying a contractive condition of integral type," International Journal of Mathematical Analysis, vol. 3, no. 26, pp. 1265-1271, 2009.

[25] M. S. Khan, "A fixed point theorem for metric spaces," Rendiconti dell'Istituto di Matematica dell'Università di Trieste, vol. 8 , pp. 69-72, 1976.

[26] V. W. Bryant, "A remark on a fixed point theorem for iterated mappings," The American Mathematical Monthly, vol. 75, pp. 399-400, 1968. 


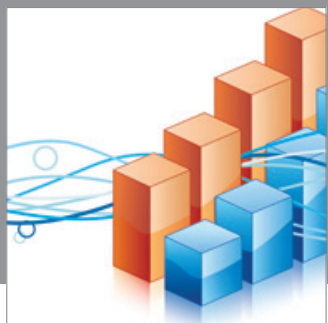

Advances in

Operations Research

mansans

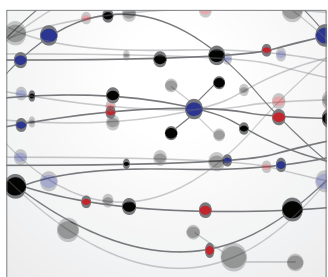

The Scientific World Journal
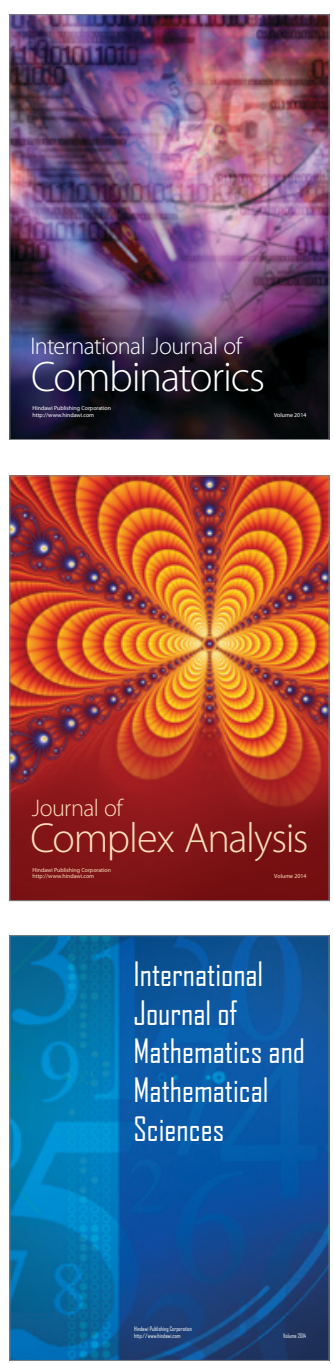
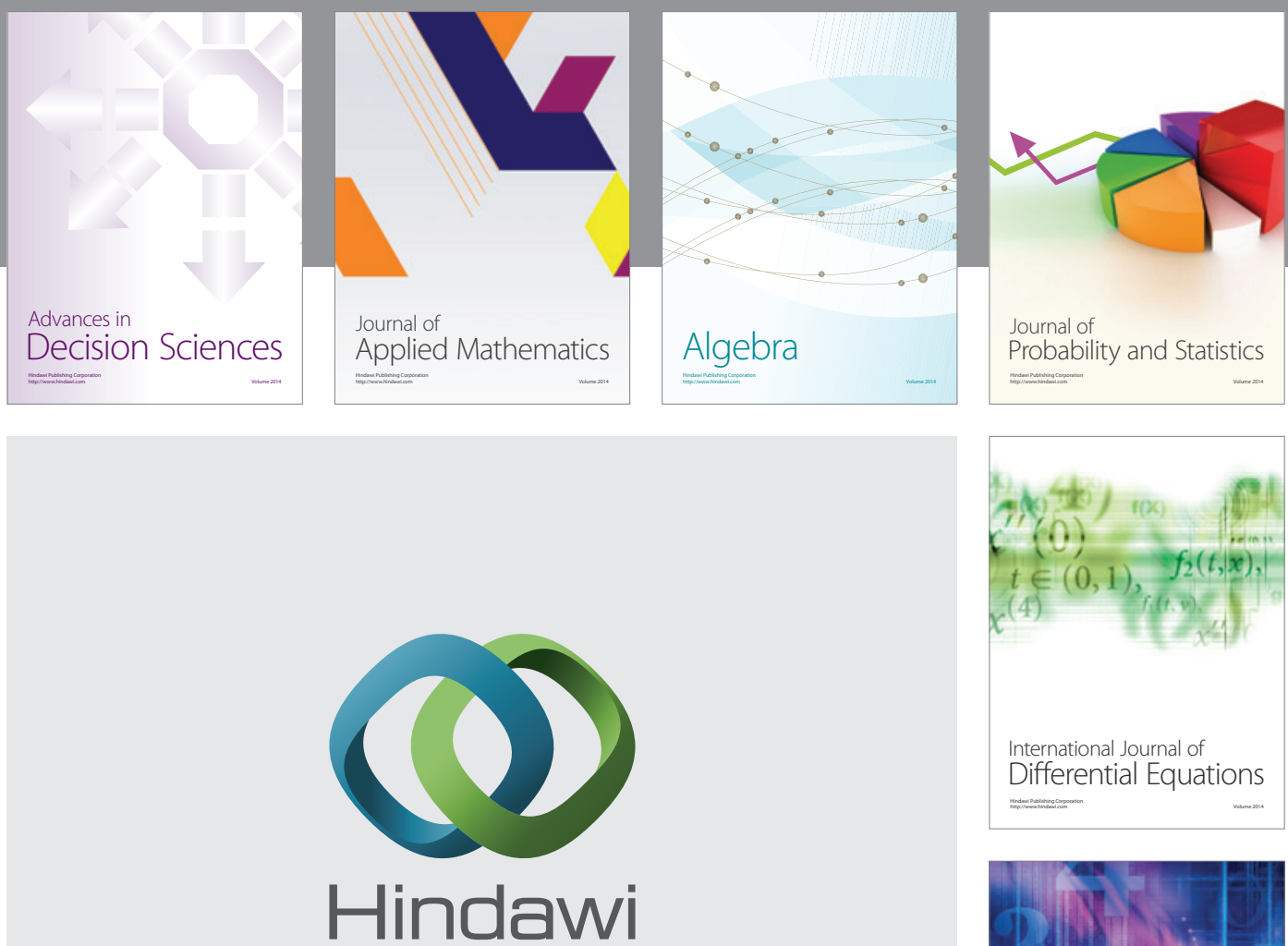

Submit your manuscripts at http://www.hindawi.com
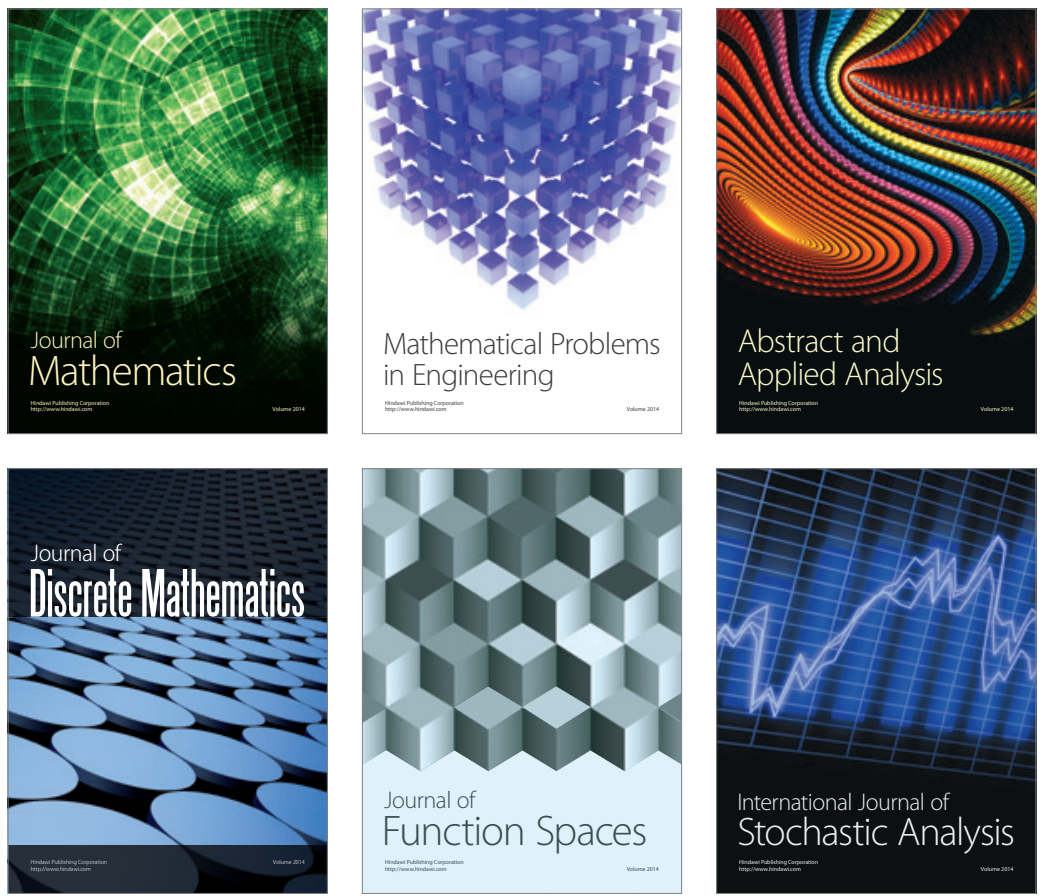

Journal of

Function Spaces

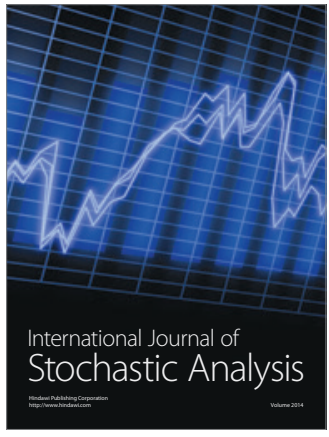

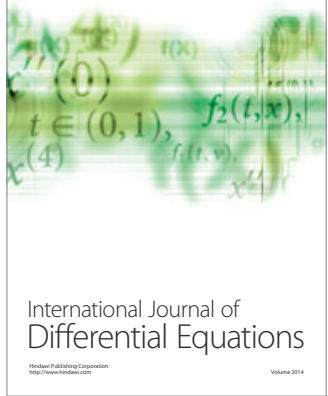
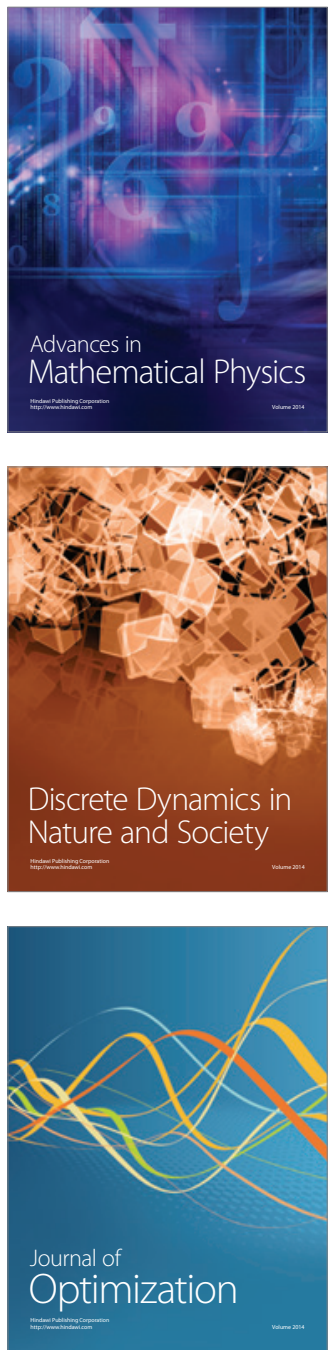